\title{
Rosuvastatin Zinc
}

National Cancer Institute

\section{Source}

National Cancer Institute. Rosuvastatin Zinc. NCI Thesaurus. Code C96308.

A zinc-containing form of rosuvastatin, a hydroxymethyl-glutaryl coenzyme A (HMGCoA) reductase inhibitor with antilipidemic activity. 